\title{
УДК 69
}

DOI $10.21661 / \mathrm{R}-496981$

\section{Л.В. Вельгас, Л.Л. Яволинская}

\section{СЕМЬ ОСНОВНЫХ ОТКРЫТИЙ СТРОГО ДОКАЗАННЫХ}

Архимед воскликнул: «дайте мне точку опоры, и я переверну землю!»

Аннотация: в нашей концепции мы стремимся доказать, что все планеть вращаются вокруг своих осей из-за воздействия своих спутников.

Вращение Совместной Силы Тяготения аналогично для всех планет и для Солнща. Солнще и каждая Планета может иметь несколько спутников. Совместная сила Тяготения каждой пары - спутника планеты и самой планеты, спутника Солниа и самого Солниа, если она, Совместная Сила Тяготения, перемещается из-за движения спутника по орбите, вращает планету или Солнце.

В статье досконально доказывается, что Совместная Сила тяготения Луны и Земли, которая перемещается по Земле из-за обращения Луны вокруг Земли, вращчает Землю вокруг её оси.

Ключевые слова: сила тяготения, вращение Земли, ось, Луна.

\section{L.V. Velgas, L.L. Iavolinskaya}

\section{SEVEN MAIN DISCOVERIES, RIGOROUSLY PROVEN}

Abstract: we are striving to prove that all planets rotate around their axis due to their satellites.

Rotation of the collateral gravitation is analogous for all the planets, for the Sun as well. The Sun, as well as every single planet, can have multiple satellites. Satellite and planet's collateral gravitation, if it moves because of satellite's movement around the orbit, rotates the planet or the Sun.

The article proves that collateral gravitation of the Moon and the Earth, that moves around the Earth due to Moon's movement around the Earth, rotates the Earth around it's axis. 
Keywords: gravitation, rotation of the Earth, axis, Moon.

И нам удалось.

Оказывается, если взять за точку опоры обычное сырое куриное яйцо, можно перевернуть мировоззрение, миропонимание не только вращения вокруг своей оси Земли, но и отсутствие вращения у Луны вокруг своей оси, и так же наличие понимания причины вращения вокруг своих осей всех планет, и не вращения вокруг своих осей у всех спутников планет.

И понимание причины вращения вокруг своей оси Солнца и даже Звёзд.

А какие чудесные следствия вращения Солнца вокруг своей оси. Это же уму непостижимо.

Первое открытие: Вращение Земли вокруг своей оси осуществляется перемещением Совместной Силы Всемирного Тяготения Луны и Земли.

Bторое открытие: У Луны есть сторона с большей массой.

Tретье открытие: Открыта причина появления магнетизма на планетах и на Солнце.

Четвёртое открытие: В том, что Магнетизм от вращения, - на самом деле, это электромагнетизм!

Пятое открытие: Энергетика Солнца не термоядерная.

Шестое открытие состоит в том, что Венера не вращается вокруг своей оси:

Седьмое открытие предполагаемое:

Вулканическая деятельность, скорее всего, следствие вращения планеть вокруг своей оси.

Ключевые слова: Магнетизм, электромагнетизм, Совместная Сила, яйцо.

Свидетели: Уран, Юпитер, Плутон и Харон, Венера, Меркурий

Первое открытие: вращение Земли вокруг своей оси совместной силой всемирного тяготения Луны и Земли 


\section{Доказательства:}

Bo-nервыx, используя, поистине, замечательные свойства сырого куриного яйца, мы поставили крест на теории инерционности постоянного вращения Земли. вокруг своей оси.

Известно, что тела, имеющие жидкости в своём строении, не вращаются по инерции. Например, сырое яйцо делает по инерции 1-2 оборота, и всё.

Надо памятник поставить сырому яйцу за его упорство, за его нежелание вращаться вокруг своей оси. Яйцо (в вопросе вращения вокруг своей оси) - аналог Земли!

Bo-вторыx, кроме того, в Первом законе И. Ньютон утверждает, что тело не может вращаться по инерции вокруг своей оси, так как сохранение постоянного движения (движения по инерции) существует, если тело выполняет ряд условий, в том числе, есть условие прямолинейного движения.

Земля не может вращаться по инерции вокруг своей оси, потому что тоже (в вопросе вращения вокруг своей оси) очень сырое яйцо (70\% воды).

Однако, Земля вращается, при чём интенсивно вращается вокруг своей оси, и это указывает на то, что должна быть, и она есть Сила не инерционная, которая это осуществляет. И она это, Совместная Сила Тяготения Земли и Луны, которая перемещается из-за движения спутника по орбите, и вращает планету или Солнце [1]. Причём,

$B$-третьих, Наибольшая сила по закону Ньютона $F=\kappa(m 1 x ~ m 2) / R^{\wedge} 2$ на поверхности тела. R-расстояние находится в делителе. Именно на поверхности наименьшее расстояние между массами тел, значит $F$ - Сила на поверхности наибольшая. Из-за перемещения Луны по орбите, сила действует касательно к поверхности. Тем самым, вращая Землю вокруг своей оси.

Примечание: Шарообразное тело можно завращать, закрутить, вокруг своей оси, воздействуя по касательной к поверхности, даже не очень большой силой.

Свидетели: теннисисты, футболисты. 
Второе открытие: у Луны есть сторона с больщей массой, это мы доказали так:

Bo-nервых - Луна природное тело, а природное тело не может быть симметричным. Всегда есть одна, более массивная сторона.

Bo-вmopblx - и именно поэтому Луна всегда повёрнута к Земле одной стороной, массивной стороной. Это действие согласно Закону Всемирного Тяготения. Это подтверждают все спутники планет. Совместная Сила Тяготения Луны и Земли держит Луну так, чтобы сторона Луны с большей массой была расположена в направлении на Землю.

Третье открытие: Причина появления магнетизма на планетах и на Солнизе.

Это мы применили принцип Ф. Араго. Явление магнетизма он наблюдал у вращающегося металлического диска. Араго назвал явление - магнетизм вращения. Он открыл, а мы применили к планетам и Солнцу. Магнетизм проявляется из-за интенсивного вращения вокруг своей оси планет и Солнца. Но:

Четвёртое открытие: магнетизм от вращуения - на самом деле это электромагнетизм!

Это мы доказываем, магнетизм от вращееия - на самом деле это электромагнетизм! потому, что диск у Араго [2] металлический, а в металлическом диске есть свободные электроны. От вращения движение свободных электронов упорядочивается. Упорядоченное движение электронов по определению это электрический Ток! Даже термины электрические вот эти - что магнетизм включается при вращении и выключается при прекращении вращения! Значит, магнетизм от вращчения, на самом деле, это - электромагнетизм!

Пятое открытие: энергетика Солнцуа не термоядерная!

Доказал Р. Дэвис [3]! Он доказал тем, что солнечных нейтрино в три раза меньше, чем должно быть, если протекает термоядерная реакция. Мы добавим, что при термоядерной реакции результатом должна быть тёмная материя, и её должно быть очень много. Пока не найдена. И непонятно откуда взялся магнетизм. И вращение Солнца ей до фени. А при электрической энергетике, и 
вращение и магнетизм необходимы. Это существенные основные подтверждающие факторы. И то, что не найдена тёмная материя, теперь уже ещё одно доказательство того, что термоядерная реакция на Солнце не идёт. А то, что энергетика электрическая - это мы доказываем на факте: электромагнетизма. Значит он, электромагнетизм, это результат появления электрического тока! $A$ mок - это тепло, свет и электромагнетизм.

Шестое открытие состоит в том, что Венера не вращзается вокруг своей ocu: [4]

Цитата:

«В результате, в каждом нижнем соединении Венера обращуена к Земле одной и той же стороной. Пока неизвестно, является ли это совпадением, или же здесь действует гравитационное притяжение Земли и Венеры».

Нас заинтересовала первая половина цитаты, что «В результате, в каждом нижнем соединении Венера обращена к Земле одной и той же стороной».

Во-первых, это, явно наблюдение, которое в принципе невозможно, если Венера вращается вокруг своей оси. Но наблюдатели, скорее всего, говорят правду, большая степень вероятности достоверности наблюдения, и это значит, что Венера НЕ вращается вокруг своей оси. Иначе они бы не увидели, что «в каждом нижнем соединении Венера обращена к Земле одной и той же стороной». Да и некому её вращать - у Венеры нет спутников. Но у Венеры есть сторона, имеющая большую массу, которая повёрнута в сторону Солнца. И которую, Совместная Сила Тяготения Венеры и Солнца всегда держит к себе этой тяжёлой стороной. И поэтому после полного оборота обращения Венеры вокруг Солнца наблюдатели Земли видят Венеру в том же положении. Если бы Венера вращалась бы вокруг своей оси, то наблюдатели этого никогда бы не увидели.

Справка: нижнее соединение - это когда Венера находится в полной фазе, по отношению к наблюдателям с Земли. Учитываем, что наблюдатели Земли не стоят на месте, а перемешаются по орбите вокруг Солнца и поэтому Венера должна ещё потратить время и пройти ещё часть своей орбиты, чтобы стала 
полная фаза. Может из-за этого разница во временах оборота вокруг оси и времени обращения вокруг Солнца? На самом же деле нет никакого времени оборота вращения Венеры вокруг своей оси. Венера не вращается вокруг своей оси. Из-за перемещения наблюдателей есть эта мнимая разница во времени.

Конечно, скорее всего, отсюда. Всё-таки мы тупые. Это же так очевидно!

Мы зацикленные были: Раз Земля, Солнце, планеты вращаются вокруг своих осей, значит все небесные тела вращаются вокруг своих осей. И тяжело воспринимать, что спутники планет, если над ними ничего не вращается, не вращаются вокруг своих осей. И планеты, так называемые планеты только потому, что они крупные, тоже оказывается, не вращаются вокруг своих осей, если не имеют спутников.

Седьмое открытие предполагаемое:

Вулканическая деятельность, скорее всего, следствие вращения планетьл вокруг своей оси.

На телах, не вращающихся вокруг своей оси нет вулканической деятельности.

Вероятно, вулканизм проявляется на тех телах, где образуется кольцьо из магмы, от скорости вращуения вокруг своей оси. Именно в этом кольце образуется электрический ток, который, во-первых, поддерживает высокую температуру у магмыл, а во-вторых, и одновременно ток создаёт сильный электромагнетизм. У Марса скорее всего нет кольцуа из магмы. У марса магнитное поле в 500 раз слабее земного.

УPAH:

«Дипольный момент превосходит земной в 50 раз [75][76]. Кроме Урана, аналогичное смещённое и «накренивщееся» магнитное поле также наблюдается и у Нептуна [76] - в связи с этим предполагают, что такая конфигурация является характерной для ледяных гигантов. Одна из теорий объясняет данный феномен тем обстоятельством, что магнитное поле у планет земной группь и других планет-гигантов генерируется в центральном ядре, а магнитное поле у «ледяных гигантов» формируется на относительно мальх глубинах: например, 8 
океане жидкого аммиака, в тонкой конвективной оболочке, окружающей жидкую внутреннюю часть, имеющую стабильную слоистую структуру» 90 [5].

Если дипольный момент на уране больще в 50 раз чем на земле, то вероятно ток на Земле примерно в 50 раз меньше, судя по формуле дипольного момента. На Уране может быть вулканизм.

$m=I$ Sn $m-$ дипольный момент

где I-сила тока в контуре, $S$ - площадь контура, $-n-е$-диничный вектор нормали к плоскости контура. [6]

На Уране тропосфера [7] самая нижняя и самая плотная часть атмосферы характеризуется уменьшением температур с высотой [11]. Температура падает от 320 К это примерно 50 градусов С,. в самом низу тропосферы (на глубине в 300 км) до 53 К на высоте в 50 км [8].

Жарче, чем у нас на экваторе. А у нас на экваторе Огненное Кольцо из вулканов.

\section{Список литературы}

1. [Электронный ресурс]. - режим доступа: https://ru.wikipedia.org/wiki/Гравитация (дата обращения: 12.05.2019).

2. Араго Ф. Магнетизм вращения. [Электронный ресурс]. - режим доступа: https://www.bibliofond.ru/view.aspx?id=73336 (дата обращения: 12.05.2019).

3. Поймать невидимку. [Электронный ресурс]. - режим доступа: http://www.vokrugsveta.ru/vs/article/218/ (дата обращения: 12.05.2019).

4. [Электронный ресурс]. - режим доступа: https://ru.wikipedia.org/wiki/Beнера\#.D0.A1.D0.BF.D1.83.D1.82.D0.BD.D0.B8.D0.BA.D0.B8 (дата обращения: 12.05.2019).

5. [Электронный ресурс]. - режим доступа: https://ru.wikipedia.org/wiki/Уран_(планета)\#Магнитосфера (дата обращения: 12.05.2019).

6. [Электронный ресурс]. - режим доступа: https://ru.wikipedia.org/wiki/Maгнитный_момент (дата обращения: 12.05.2019).

7. [Электронный ресурс]. - режим доступа: https://ru.wikipedia.org/wiki/Уран_(планета) (дата обращения: 12.05.2019). 


\section{References}

1. ru.wikipedia.org.

2. Arago, F. Magnetizm vrashcheniia.

3. Poimat' nevidimku. Retrieved from http://www.vokrugsveta.ru/vs/article/218/

4. https:. ru.wikipedia.org.

5. https:. ru.wikipedia.org.

6. https:. ru.wikipedia.org.

7. https:. ru.wikipedia.org.

Вельгас Лев Борисович - изобретатель-раџионализатор, научный практик, Россия, Москва.

Velgas Lev Borisovich - inventor-innovator, research expert, Russia, Moscow.

Яволинская Лия Львовна - координатор МБО «Возрождение», Россия, Москва.

Iavolinskaya Liia Lvovna - coordinator at the $M B O$ «Vozrozhdenie», Russia, Moscow. 